\title{
CHORIRO: A UTOPIA QUE SE FEZ VERBO
}

\section{CHORIRO: THE UTOPIA BECAME VERB}

\author{
Adilson Fernando Franzin ${ }^{1}$
}

\section{RESUMO}

Ungulani Ba ka Khosa é considerado um dos escritores mais importantes da literatura moçambicana, sobretudo, por colmatar ficcionalmente não apenas as lacunas deixadas pela historiografia que se debruça sobre o período colonial de seu país, mas também por questionar de modo frontal as complexas decisões políticas tomadas pelo governo de Moçambique no momento pós-independência. Com o olhar voltado para o século XIX, o presente estudo tenta compreender como o autor entrelaça ficção a elementos históricos para lançar luz sobre o passado e legitimar vozes que são frequentemente excluídas dos discursos oficiais.

PALAVRAS-CHAVES: Ungulani Ba Ka Khosa; Ficção; História

\section{ABSTRACT}

Ungulani Ba ka Khosa is considered one of the most important writers of Mozambican literature, mainly for filling fictionally not only the gaps left by the historiography that focuses on the colonial period of his country, but also to question in a frontal way the complex political decisions taken by the Mozambican government at the time of independence. Looking back to the nineteenth century, the present study tries to understand how the author intertwines fiction with historical elements to shed light on the past and to legitimize voices that are often excluded from official discourses.

KEYWORDS: Ungulani Ba Ka Khosa; Fiction; History 
Desde 1987, com a publicação de Ualalapi, livro que integra a lista dos cem melhores autores africanos do século XX, Ungulani Ba Ka Khosa tem mantido sua letra em riste, sagrando-se como um dos escritores mais importantes de Moçambique. Sua importância no panorama da literatura moçambicana deve-se, sobretudo, pelo fato de questionar de maneira frontal as decisões políticas postas em prática a partir da independência, em 1975, como igualmente colmatar e perquirir as possíveis lacunas deixadas pela historiografia sobre seu país. Dessa forma, tendo como pressuposto um olhar endógeno, o escritor moçambicano reescreve criticamente o ethos de suas gentes através do texto literário, propondo, pois, novas perspectivas para iluminar o passado e compreender o presente.

O romance intitulado Choriro teve sua primeira edição em 2009, com a chancela da editora Alcance, de Maputo. Posteriormente, em 2015, uma edição portuguesa, profundamente revista pelo autor, foi lançada pela Sextante, na cidade do Porto. Diante dessas páginas, é de se salientar que novamente a preocupação literária de Ungulani Ba Ka Khosa se envereda pelo século XIX na tentativa de entender os primórdios de Moçambique, como ele já bem o fizera em Ualalapi, ao trazer à tona as tramas da sucessão do Império de Gaza. Assim, munido de saberes historiográficos e etnográficos notáveis, o escritor moçambicano humaniza inúmeros personagens históricos entre outros que retira de seu imaginário, lidando intensamente com os porosos limites ficcionais e históricos.

Ademais, não seria inconveniente lembrar que "um dos maiores depositários das vivências privadas ou coletivas, das tensões, contradições, aspirações, frustrações e das tendências mais profundas de uma sociedade é o imaginário (NOA, 2015, p. 356)", sendo a literatura sua expressão mais dinâmica. No entanto, a tônica que permeia a narrativa de Choriro, a qual simultaneamente esclarece e confunde o leitor sobre a oficialidade do discurso ali expresso, é sem dúvida o questionamento da práxis histórica:

Uma, entre outras questões que se colocam ao ler-se o último romance de Ungulani Ba Ka Khosa, Choriro, é a do conhecimento. Trata-se de um apelo a uma discussão epistemológica sobre os desafios que se colocam, num primeiro plano, à ciência histórica, essa narração metódica de passados, na produção do conhecimento a partir de um olhar local, de dentro (MANJATE, 2011, p. 1).

Como preâmbulo de nosso estudo, podemos adiantar que a proposta dialógica entre literatura e história é estabelecida logo no paratexto de Choriro, figurando na "nota do autor" que abre o romance, a qual poderá funcionar como uma importante chave de leitura:

Este retrato de um espaço identitário, de uma utopia que se fez verbo, assentou na rica e impressionante história do vale do Zambeze no chamado período mercantil. A intenção do livro foi a de resgatar a alma de um tempo, a voz que não se grudou aos discursos dos saberes. O fundamento histórico 
valeu-me como porta de entrada ao mundo de sonhos e angústias por que o vale do Zambeze passou durante mais de quatro séculos (KHOSA, 2015, p. 7).

O contexto no qual a narrativa de Choriro se desenrola é o período chamado de colonialismo mercantil, cujos prazos da $\mathrm{Coroa}^{2}$ constituem uma das características mais marcantes da história de Moçambique. Tal processo foi paulatinamente engendrado numa complexa relação colonial entre a Coroa Portuguesa e os habitantes do ainda disforme território moçambicano, o que se passa no século XVI até a década de trinta do século XX (NEWITT, 1997, p. 203). Contudo, o romance de Ungulani Ba Ka Khosa é projetado temporalmente na metade do século XIX, entre as décadas de 1940 e 1980, e, geograficamente, no território Chicunda que se localiza a oeste de Moçambique entre a parte ocidental do Zambeze e o rio Luangwa, situado um pouco mais ao norte.

Porém, o texto também faz alusão ao constante trânsito comercial e aos conflitos da região zambezeana que se estende do Tete ao Sena, sempre às margens do rio Zambeze, cuja importância no enredo do romance está para além de algo meramente paisagístico ou espacial. Dessa forma, o rio e suas volumosas águas podem ser lidos como prosopopeia e compreendidos como personagem imprescindível para a articulação da narrativa, além de reforçar o cariz animista de tradições seculares africanas, nas quais entes da natureza agem deliberadamente, possuindo cada qual a sua "alma" própria, "pois onde canta a água do rio, é sinal de alegria e fartura, porque o peixe abunda (KHOSA, 2015, p. 157)".

Com efeito, os prazos foram formados principalmente por colonos não obrigatoriamente de origem lusa, por afro-portugueses e indianos submetidos aos mandos de Portugal para impor sua soberania e fazer jus ainda a uma ideia de império ultramarino. Ora, os prazeiros, como eram chamados, estabeleciam laços matrimoniais com filhas de chefes locais e, sob a égide do estatuto de branco ou de não indígena, gozavam de muitos privilégios comerciais, bélicos e tributários. No entanto, como se verificou em muitos casos, não honravam os compromissos firmados com a metrópole lisboeta que lhes cedera terras mediante a assinatura de contratos de arrendamento. Dessa forma, perante as regras imperiais, o período de posse de tais territórios correspondia a três gerações, somente transmitidos por via matrilinear, o que conferiu muito poder a alguns colonos, igualmente a um número restrito de mulheres que ficaram conhecidas como as "donas do Zambeze".

Todavia o mau gerenciamento colonial português na África, devido principalmente à escassez de efetivos militares, fez com que o poderio individual dos colonos alçados à categoria de senhores de prazos fosse aumentando, ao passo que o conhecimento destes em relação ao modus vivendi de várias etnias instaladas ao longo do vale do Zambeze também ganhasse em espessura. Consequentemente, não tardou para que eles se 
constituíssem em estados secundários marcadamente tirânicos, desvencilhando-se da Coroa Portuguesa. Na teoria, acatavam as ordens metropolitanas, mas, na prática, não as cumpriam, munidos por numerosos exércitos particulares de achicundas ${ }^{3}$, os quais buscavam proteção ante um sistema ávido em abarrotar os porões dos navios negreiros, pois "tornara-se hábito dos senhores de prazos deixarem o marfim por acharem que os escravos eram mais lucrativos nas trocas comerciais (KHOSA, 2015, p. 67)". Convertido voluntariamente em mambo, isto é, em rei, chamado de Nhabezi em língua nativa africana, certamente se enquadra no perfil descrito de prazeiro, que em momento posterior teve seu próprio reino, súditos leais, além de se beneficiar dos laços poligâmicos de suas seis esposas.

Tanto como matéria pertinente para conjecturar uma possível gênese romanesca de Choriro como para esboçar sua síntese, podemos observar através do fragmento abaixo a importância do lastro histórico neste recorte de época colonial a respeito de Moçambique, que de certa forma tem sua relevância e está ficcionalmente representado na narrativa:

Era com frequência que os chicunda se revoltavam, sendo que alguns optando por gerir o prazo de acordo com os seus próprios interesses, cobrando eles mesmos o tributo dos colonos e estabelecendo uma espécie de república independente. Sempre que um senhor do prazo morria, o acontecimento era aproveitado enquanto pretexto para a organização de pilhagens, levando assim a população a "chorar" o falecido prática esta que era observada nas chefias vizinhas. À medida que os filhos sucediam aos pais e aos avôs dentro da comunidade chicunda, a sua identidade étnica ganhava contornos específicos, possuindo eles as suas aldeias, bem como as suas organizações sociais e políticas - ou seja, acabavam por constituir uma casta a parte dentro da população que ocupava as terras baixas do Zambeze (NEWITT, 1997, p. 218).

Com base nessa mesma ideia de celebração fúnebre e suspenção da ordem estabelecida, Ungulani Ba Ka Khosa - aliás, como tem praticado através de um exercício altruísta e metalinguístico ao longo de sua obra, para além de glossários contendo léxicos específicos de etnias moçambicanas - explica-nos com algum pormenor o título do romance:

Os achicundas, mais serenos, limpavam as lanças e as gogodelas. As danças guerreiras em honra do finado iriam preencher os três dias de luto, termo aqui empregue e assumido numa asserção fúnebre de amplitude alargada, pois para eles a morte do suserano era sentida em choros e anarquia que podiam levar a assassinatos sem julgamento porque nos três dias de ausência de poder tudo era permitido, daí o termo choriro, que em tradução franca se pode dizer choro pela ausência de ordem (KHOSA, 2015, p. 27).

É de se notar que ao encaminhar a diegese para o desfecho, o escritor moçambicano ilustra com maior rigor as consequências da morte de Nhabezi, nome que Gregódio adotara por representar entre os achicundas 
a figura de um grande curandeiro branco. Além disso, pelo excerto a seguir, fica evidente a crítica contumaz direcionada à história submetida pela literacia que privilegia os nobres e valentes, invariavelmente os detentores do poder, sempre a figurar como os diletos protagonistas dos discursos históricos oficiais, em detrimento do silenciamento e obliteração de outras vidas com suas estilhaçadas narrativas:

Muito terá acontecido nas vésperas. Sabe-se que houve mais nascimentos que mortes na semana de luto. As crianças nadas em tal período, e em respeito ao finado, foram sendo nomeadas Nhabezi ou Gregódio. Entre os mais de três mil achicundas que constituíam o exército de Nhabezi, reportaram-se casos de luta que culminaram com trinta óbitos em todo o território; número insignificante para causar choros colaterais, mas suficiente para recordar, em tempos vindouros, o choriro em memória do Nhabezi. Na fronteira mais a sul, duas aldeias foram arrasadas por caçadores de escravos. Foram saqueadas presas de elefante em trânsito. Homens e mulheres tornaram-se prisioneiros. Trinta a quarenta camponeses foram dizimados pelo chumbo dos caçadores. Distantes, e bastante absorvidos com a bebida e o luto, os achicundas responsáveis pela segurança não ripostaram. À pessoa de Makula Ganunga, o muanamambo, fizeram chegar, em ordem de balanço, a informação de que na autoria do álcool e do luto, duas aldeias viram as casas comidas pelo fogo. O recenseamento populacional invocaria o feitiço e doenças como causadoras do fogo e da morte. Mas todos os acontecimentos marginais à dor real ficaram ligados à memória dos acontecimentos reais. No calendário local, o tempo passou a ser dividido entre antes e depois da morte de Nhabezi.

Dos acontecimentos das vésperas, o que em letra ficou foram os registos de Chicuacha, o andarilho. Do mundo vivido, da memória popular, sobraram ecos, pequenos cacos (KHOSA, 2015, p. 133).

As reflexões de Jacques Rancière, a respeito da história enquanto ciência, presentes em Todos os nomes da história, serve-nos como substrato teórico, uma vez que Ungulani Ba Ka Khosa manipula e presume em linguagem romanesca o que o filósofo francês parece construir como poética do saber, lançando, pois, luz sobre nosso debate:

Uma história, em sentido comum, é uma série de acontecimentos que se passam com sujeitos geralmente designados por nomes próprios. Ora, a revolução da ciência histórica quis justamente revogar o primado dos acontecimentos e dos nomes próprios em benefício dos longos períodos e da vida dos anônimos. Foi assim que ela reivindicou ao mesmo tempo seu pertencimento à era da ciência e à era da democracia. Num segundo nível, uma história é também a narrativa dessas séries de acontecimentos atribuídas a nomes próprios. E a narrativa se caracteriza comumente por sua 
incerteza quanto à verdade dos acontecimentos relatados e à realidade dos sujeitos aos quais eles são atribuídos (RANCIÉRE, 2014, p. 1-2).

E o filósofo, ao dar continuidade a seu pensamento, atinge o cerne das questões que envolvem literatura e história que aqui nos são caras:

As coisas seriam muito simples se pudéssemos dizer que toda história, como diz a expressão consagrada, é apenas uma história. É próprio de uma história sempre poder ou não poder ser uma história. As coisas também seriam muito simples se a certeza dos acontecimentos acompanhasse a dos sujeitos. Mas é sempre possível atribuir acontecimentos verídicos a sujeitos de ficção ou de substituição e acontecimentos incertos ou fictícios a sujeitos reais. A história divertida e o romance histórico vivem das voltas e reviravoltas permitidas por essa indeterminação (RANCIĖRE, 2014, p. 2).

Ora, por mais que a episteme histórica tenha evoluído através dos séculos, sobretudo com a École des Annales, para os objetivos deste trabalho que almeja compreender Choriro e suas relações com a história, estamos essencialmente ainda na esteira da antiquíssima diferenciação aristotélica feita entre o historiador e o poeta, isto é, em torno das elucubrações do filósofo grego em relação ao que aconteceu e ao que poderia ter acontecido, bem como seu respectivo compromisso com a "verdade" historiadora e a dimensão filosófica da literatura (ARISTÓTELES, 1993).

No caminho para melhor visualizar os procedimentos de feitura do romance, podemos observar que na sequência da "nota do autor" citada anteriormente, Ungulani Ba Ka Khosa explicita as referências históricas que foram úteis para a composição de Choriro. Assim, cientes dessas fontes, posteriormente poderemos tecer algumas importantes considerações:

Aos que me abriram as portas, a referência maior fica para Allen e Barbara Isaacman, casal iluminado na reconstrução do edifício social, económico, político e cultural do vale do Zambeze desde a primeira escopetada de um desconhecido português em finais do século XVI. Outras portas e janelas foram franqueadas no inesgotável manancial que o Arquivo Histórico oferece aos que buscam tochas para o seu passado (KHOSA, 2015, p. 7).

Provavelmente, ao deixar registrado os nomes de Allen e Barbara Isaacman, Ungulani Ba Ka Khosa esteja nos remetendo à obra intitulada A tradição de resistência em Moçambique: O Vale do Zambeze, 1850-1921, publicado em 1979, cujo conteúdo é indubitavelmente uma fonte de informações muito importantes para a compreensão da época na qual Nhabezi, e o choriro desencadeado por seu falecimento, são historicamente situados, sendo o segundo capítulo, "O crescimento dos estados secundários e a conquista do vale do Zambeze", o mais relevante e o que mais pode ser percebido subjazendo ao texto ficcional como um verdadeiro palimpsesto. 
Vale a pena lembrar algumas estratégias literárias que fizeram de Ungulani Ba Ka Khosa, ao longo de mais de três décadas de carreira, uma espécie de porta-voz dos preteridos e silenciados da história. Por exemplo, em Ualalapi, embora a narrativa tenha se centrado na figura ambígua do último imperador de Gaza, Ngungunhane, o escritor moçambicano optou por rotular a obra com o nome do personagem responsável por matar Mafemane, o qual teria prioridade em herdar o ambicionado trono. Logo, Ualalapi, que com tal ato modificara decisivamente o curso da história moçambicana, valendo-lhe desse homicídio a sua loucura - uma vez que ensandece após cometer tal crime - não fosse a letra diligente de Ungulani, talvez tivesse seu nome esfumado nas brumas do tempo.

Outrossim, é o caso verificado em No reino dos abutres, romance de 2002, no qual o índice se apresenta anunciando os vários movimentos do ngodo - performance étnico-cultural orquestral formada por timbilas e seus respectivos músicos e dançarinos. No entanto, no interior da narrativa tal fato não se verifica, ludibriando o leitor (ou censor) desavisado, caso este se restrinja apenas à costumeira olhadela no paratexto do livro, quando, na verdade, a diegese propriamente dita se adensa na denúncia da política malfadada dos campos de reeducação posta em prática pela Frelimo. Em suma, é muito por causa desse ardil que o organizador e co-autor Niyi Afolabi, em 2010, tomando a frente do principal estudo publicado a respeito da obra khosiana até os dias atuais, o livro intitulado Emerging Perspectives on Ungulani Ba Ka Khosa, rende-lhe, entre outros atributos, os epítetos de "trickster" e "provocateur" no sentido positivo dos termos, que reflete inequivocamente a imagem de um literato experimentado.

Em vista disso, como tentaremos demonstrar, haverá também por parte de Ungulani Ba Ka Khosa alguma artimanha na construção de Choriro que o leitor comum, sem uma prévia e refletida investigação histórica, não será capaz de perscrutar no jogo operado entre ficção e realidade, julgando a seu turno todos os personagens, ou pelo menos os fundamentais, como verdadeiramente partícipes da história colonial de Moçambique, uma vez que seus nomes podem ser facilmente encontrados na historiografia moçambicana.

Considerando as pistas de Ungulani Ba Ka Khosa que levam ao casal Isaacman, muitos personagens que deambulam nas tramas de Choriro estão documentados em A tradição de resistência em Moçambique: $O$ Vale do Zambeze, 1850-1921, como é o caso de Chicuacha, o ex-padre que fora amigo íntimo de Nhabezi, seu cronista e confidente, largando a batina e aculturando-se entre os cafres. Igualmente os senhores de estados secundários, como Matakenya, Kanyemba e Carazimamba, exímios estrategistas militares à frente de seus exércitos de escravos-guerreiros achicundas, os quais constam tanto no romance quanto no referido livro de história.

A curiosidade, ao seguirmos os rastros da poética de Choriro, é que nem o nome português, Luís António Gregódio, nem Nhabezi, alcunha do mambo entre os achicundas, constam no trabalho de Allen e Barbara Isaacman, fato que tende a tornar mais complexo o jogo histórico-ficcio- 
nal veiculado na narrativa e, para a crítica literária, sinal de uma evidente mudança de cunho genológico, ou seja, de romance histórico - nos moldes consolidados por Walter Scott no século XIX -, para a pós-modernista e contemporânea metaficção historiográfica (HUTCHEON, 1991).

De resto, é a questão dos nomes próprios, no seio da história de que falava Rancière ainda há pouco, que deve ser redimensionada numa outra lógica, como sugere Ungulani, a partir do momento em que estamos, na ambiência de Choriro, diante de sociedades ágrafas cujo maior meio de difusão cultural é a oralidade. Com efeito, cabem as indagações: somente os seletos grupos de personagens presentes na historiografia com seus nomes próprios poderiam compor as narrativas basilares de um determinado povo? O protagonismo de uma personagem fictícia em meio a outras ditas "reais" invalida ou reduz o valor do discurso literário? Então, o que acontece "com a voz que não se grudou aos discursos dos saberes" (KHOSA, 2015, p. 7)? Essas e outras questões são levantadas sutilmente ao longo do romance com o intuito de moderar e relativizar o discurso hegemônico ocidental em prol de valorar o ser/estar africano no mundo e seu modo outro de lidar com o passado, tornando-o sujeito e não objeto de sua própria arte e de sua própria história.

Ainda em consulta à obra do casal Isaacman, constatamos o nome do ex-clérigo Chicuacha anexado à lista dos reis de Macanga, área situada a norte do Zambeze. Assim, tendo ele verdadeiramente governado essa região entre os anos de 1870 e 1874, no romance, será apenas representado como eficiente cronista, portador de uma voz profética e apocalíptica, a qual desempenha um importante papel no relato presente nas últimas páginas de Choriro, do qual podemos ler as seguintes palavras:

Os espíritos, a existirem, definharão na memória de gerações que desbravarão sem medo, e a mando de outros reis, os bosques sagrados à procura de outras riquezas. Os mapas da memória perderão a cor e o vigor de outrora. Na verdade, seremos o sonho de nós mesmos (KHOSA, 2015, p. 155).

Outro personagem histórico que ganha relevo nas páginas de Choriro é Livingstone (1813-1873). Médico, missionário e explorador, de 1851 até sua morte, na África Central, o escocês viveu num território que percorrera extensamente. Assim, foi o primeiro europeu a dar notícia do alto Zambeze (COSTA e SILVA, 2012, p. 396). Desse modo, o narrador relata que ao fazer a travessia de Luanda a Quelimane, de oeste a leste da parte central do continente africano, num trajeto que enquadrava o famoso Mapa Cor-de-Rosa elaborado pelo ministro português Barros Gomes, que os portugueses tanto almejaram como projeto colonial, Livingstone teve as seguintes impressões:

(...) se deslumbrou ao avistar, a cerca de cem metros de altura, as águas do Zambeze, em mais de mil e setecentos metros de largura, desprendendo-se em nuvens turbulentas de água em pó alcandorando-se a mais de quinhentos metros do verde frondoso de terras que viriam a estar sob custódia da rai- 
nha Vitória, nome com que batizara as conhecidas cataratas do Zambeze, ignorando o mosi ao tunya, o fumo que troveja, designação por que eram localmente conhecidas (KHOSA, $2015,106)$.

Em relação ao aspecto utópico ou à "utopia que se fez verbo", retomando as palavras de Ungulani Ba Ka Khosa, sintagma que também reverbera ecos do Gênesis e do Evangelho de João, Choriro parece sedimentar um esforço literário para conceber uma origem ou fundação nacional, isto é, um começo formador da identidade moçambicana moderna. Por conseguinte, é muito devido ao retrato traçado de Nhabezi e pelo seu convívio respeitoso com a corte, acólitos e esposas que a ideia de utopia pode ser amalgamada através desse personagem branco aculturado entre os africanos à rebours da gesta colonial a qual se arrastou de modo atroz e arbitrário ao longo de três quartos do século XX. Assim, quanto à ficcionalidade da figura de Nhabezi, Vanessa Ribeiro Teixeira nos concede seu contributo:

Independentemente da existência ou não de António Gregódio, a diversidade cultural e as reticências históricas da região do Zambeze favorecem a criação de "estórias" - aqui entendidas como "micro-possibilidades" históricas - pautadas pelo mote "bem que poderia ter sido" (TEIXEIRA, 2014, p. 116-117).

Acrescentaríamos ainda às estórias de Choriro, que afrontam a História de Moçambique, traços de elegia - composição poética que em suas origens na Grécia Antiga era especialmente composta como música para um funeral ou lamento de morte, como é o caso do romance por nós cotejado. Literariamente, a elegia, embora seja expressa em forma de poesia, traz sempre um tom de arraigada tristeza e melancolia. Com efeito, a espraiar os limites dos gêneros literários, o escritor moçambicano parece diluir alguns desses elementos elegíacos no incipit da narrativa, substituindo a melodia - elemento musical muito valorizado no Ocidente - pela rítmica percussiva com acentos notadamente africanos: "A notícia correu célere. Os batuques, em profundos e largos tons, rufaram em toda a plenitude durante três dias e três noites por todo o reino (KHOSA, 2015, p. 11)."

É bom lembrarmos que o século XIX, decisivo para a evolução das ciências, é também o momento de maior evidência de que "a África aparece cada vez mais como um continente perversamente imperfeito, que a Europa tinha o dever moral de tirar da escuridão e pôr nos eixos." Ora, "iam-se tecendo assim as justificativas para o domínio colonial sobre o continente (COSTA e SILVA, 2012, p. 13)", por isso que o português Gregódio, absorvendo voluntariamente a cultura africana e reinserindo-se socialmente no vale do Zambeze como Nhabezi, personifica o signo da utopia de um tempo que jamais se repetiu nas relações coloniais entre Portugal e Moçambique. Entretanto, se Nhabezi é fruto do imaginário de seu criador, a aculturação que lhe foi atribuída, como veremos, tratou-se de uma circunstância histórica inédita: 
A adoção dos elementos culturais indígenas estendeu-se para além da assimilação do artesanato, técnicas e línguas locais, o que facilitou a sua adaptação a um ambiente novo e difícil. (Os prazeiros) adotaram igualmente as instituições e valores das culturas indígenas (...). Este padrão de aculturação apagou as distinções entre governantes estrangeiros e os seus súditos locais, e em certos casos contribuiu para aumentar a legitimidade da elite governante (ISAACMAN, 1979, p. 66-67).

Porém, esse tipo de cenário formado com contornos utópicos, de brandas relações entre grupos específicos de colonos e africanos em pleno desenvolvimento do tráfico negreiro só foi possível, na metade do século XIX, devido a um colonialismo ainda incipiente perto daquele que Moçambique iria experimentar anos mais tarde, principalmente depois da Conferência de Berlim e a consequente partilha da África. Em vista disso, o antropólogo José Luís Cabaço nos ajuda a compreender este capítulo seguinte do jugo colonial, o qual, ao fim e ao cabo, foi o mais marcante:

A sociedade colonial em África concebe-se e organiza-se em função de uma multiplicidade de dualismos: frente a frente, bem marcados, estarão não apenas "branco e preto", "indígena e colonizador", mas também "civilizado e primitivo", "tradicional e moderno", "cultura e usos e costumes", "oralidade e escrita", "sociedade com história e sociedade sem história", "superstição e religião", "regime jurídico europeu e direito consuetudinário", "código do trabalho indígena e lei do trabalho", "economia de mercado e economia de subsistência", etc., todos eles conceitos marcados pela hierarquização, em que uns se apresentam como a negação dos outros e, em muitos casos, como a sua razão de ser (CABAÇO, 2010, p. 36).

No entanto, para Nhabezi os estigmas de superioridade europeia ficaram para trás, assim como o seu incomum sobrenome, Gregódio, que estranhamente carrega o vocábulo "ódio" consigo - sentimento que certamente permearia uma ou outra dicotomia acima referida até a independência de Moçambique. Assim, pelo fragmento a seguir podemos vislumbrar o modo pelo qual Nhabezi aumentou consideravelmente suas hostes, além da justificativa para seu nome honorífico africano, que significava o grande curandeiro branco:

Querendo uma autonomia espiritual que o levasse a invocar os espíritos ancestrais achicundas a que chamavam de muzimu, Nhabezi foi introduzindo espécies de árvores apropriadas aos rituais dos antepassados achicundas. Sem se divorciar dos cerimoniais clânicos matrilineares, rituais patrilineares típicos achicundas foram-se introduzindo graças à chegada de mais guerreiros fugidos da escravidão, de gente proscrita e de pessoas que desertavam das secas cíclicas das agrestes terras próximas de Tete. A todos Nhabezi recebia. 
Uns quebravam o mitete, outros integravam-se simplesmente. O exército era respeitado nas redondezas. Grupos nguni não se atreviam a molestar as populações na colecta dos habituais impostos. O branco Nhabezi era rei e senhor de vastas terras na confluência dos rios Lângua e Zambeze. Cruzavam-se no seu reino povos matrilineares e patrilineares, mas o poder achicunda, tipicamente patrilinear, foi prevalecendo sobre os casamentos e sucessões (KHOSA, 2015, p. 39)

A inversão da noção de pertencimento entre o universo português e moçambicano é bastante exemplar na narrativa de Choriro, não apenas na figura de Nhabezi, mas também de Chicuacha, antigo eclesiástico, cujo nome luso é António Gonzaga, pois no território do ultramar, adentrando-se pelo século XX e intensificando-se o salazarismo, o que se constata é o fato de majoritariamente o africano ou mestiço querer assimilar a cultura portuguesa para tentar melhorar o seu estatuto de subalterno. Isto posto, muitos estereótipos que permanecem até os dias atuais a respeito da África grassaram no século XIX, momento em que se acreditava serem os africanos seres a-históricos, como afirmou o filósofo alemão Friedrich Hegel:

A África propriamente dita é a parte característica deste continente. Começamos pela consideração deste continente, porque em seguida podemos deixá-lo de lado, por assim dizer. Não tem interesse histórico próprio, senão o de que os homens vivem ali na barbárie e na selvageria, sem fornecer nenhum elemento à civilização. Por mais que retrocedamos na história, acharemos que a África está sempre fechada no contato com o resto do mundo, é um Eldorado recolhido em si mesmo, é o país criança, envolvido na escuridão da noite, aquém da luz da história consciente (...). Nesta parte principal da África não pode haver história (HEGEL, 1928, p. 187).

Ora, Ungulani Ba Ka Khosa, ele próprio um estudioso da História, está ciente das lógicas de subordinação, da dispersão dos atributos da soberania e da dificuldade em inscrever-se como sujeito da história, pois, em pleno século XXI, mulheres e homens de África ainda se encontram submetidos a velhos paradigmas, a antigos exotismos, à mera curiosidade etnológica, à suspeita de não serem muito profícuos no âmbito da literatura, pois a supremacia da cultura ocidental e a infeliz imagem que Hegel fez do continente permanecem latentes nas mentes mais recalcitrantes.

Em suma, ao trabalhar as potencialidades romanescas nos limites da crença cientificista da história, o escritor fez ecoar em Choriro palavras que jamais foram ditas, os silêncios e as fermatas da história moçambicana que paradoxalmente estão prenhes de sentido, as quais podem e devem ser discutidas no âmbito das humanidades. Por conseguinte, a letra sempre em riste de Ungulani Ba Ka Khosa imprime inevitavelmente na literatura de Moçambique, sobretudo através da figura emblemática do "branco-preto" Nhabezi - a utopia que se fez verbo -, uma rara marca de alteridade. 


\section{REFERÊNCIAS BIBLIOGRÁFICAS}

AFOLABY, Niyi. Emerging Perspectives on Ungulani Ba Ka Khosa. Trenton, NJ: Africa World Press, 2010.

ARISTÓTELES. Poética. Trad. Eudoro de Sousa. $3^{\circ}$ ed. São Paulo: Ars Poética, 1993.

CABAÇO, José Luís. Moçambique: Identidades, Colonialismo e Libertação. $1^{\circ}$ ed. Maputo: Marimbique, 2010.

COSTA e SILVA, Alberto da (org.). Imagens da África. Da Antiguidade ao século XIX. $1^{\circ}$ ed. São Paulo: Penguin \& Companhia das Letras, 2012.

HEGEL, Georg Wilhelm Friedrich. Filosofia de la historia universal. Madri: Revista de Occidente, 1928, t. I.

ISAACMAN, Allen; ISAACMAN, Barbara. A tradição de resistência em Moçambique: O Vale do Zambeze, 1850-1921. $1^{\circ}$ ed. Porto: Afrontamento, 1979.

KHOSA, Ungulani Ba Ka. Choriro. $1^{\circ}$ ed. Porto: Sextante, 2015.

MANJATE, Lucílio. “Como é que se escreve 'choriro'?”. In: O País, 2011. Disponível em: <http://www.buala.org/pt/a-ler/como-e-que-se-escreve-choriro> Acesso em: 26 de maio de 2018.

NEWITT, Malyn. História de Moçambique. Trad. Lucília Rodrigues e Maria Georgina Segurado. $1^{\circ}$ ed. Mem Martins: Publicações Europa-América, 1997.

NOA, Francisco. Mito, Império e Miopia: Moçambique como invenção literária. $1^{\circ}$ ed. São Paulo: Kapulana, 2015.

RANCIÈRE, Jacques. Os nomes da história: ensaio de poética do saber. Trad. Maria Echalar. $1^{\circ}$ ed. São Paulo: Editora Unesp, 2014.

TEIXEIRA, Vanessa Ribeiro. De Gaza ao Zambeze: a reinvenção da história em Ualalapi e Choriro, de Ungulani Ba Ka Khosa. Mulemba. Rio de Janeiro: UFRJ, V.1, n.10, p. 110-121, jan. 2014.

Recebido para publicação em 30/05/2018

Aprovado em 13/08/2018

\section{NOTAS}

1 Doutorando em Estudos Portugueses pela Université Paris-Sorbonne, em Teoria Literária e Literatura Comparada pela Universidade de São Paulo.

2 Desde fins do século XVI, ao longo do vale do Zambeze, os portugueses instituíram os chamados "prazos da Coroa” para tentar ocupar Moçambique de maneira efetiva. Assim, os colonos enviados para este vasto território recebiam estas terras da Coroa Portuguesa com o dever de explorá-las. Para tanto, casavam-se principalmente com as filhas dos chefes locais, pois a posse de tais territórios, conforme o estabelecido pelo Estado colonial, só poderia ser transferida por via feminina e com a duração de três gerações.

3 Achicundas eram escravos-guerreiros a serviço da administração colonial e dos senhores dos prazos da Coroa, imprescindíveis para a sociedade mozungo, termo utilizado para designar homens de famílias mestiças e líderes de milícias especiais. 